\title{
CIDADES NA AGRICULTURA CIENTÍFICA E GLOBALIZADA: TRANSFORMAÇÕES NA DINÂMICA DA POPULAÇÃO E NA ESTRUTURA DO EMPREGO
}

\author{
Cities in Scientific and Globalized Agriculture: Transformations in the Dynamics \\ of Population and in the Structure of Employment
}

\author{
Natália Belmonte Demétrio* \\ Rosana Baeninger **
}

\begin{abstract}
*Núcleo de Estudos de População Elza Berquó/Universidade Estadual de Campinas - ndemetri@unicampbr ** Instituto de Filosofia e Ciências Humans/Núcleo de Estudos de População Elza Berquó/Universidade Estadual de Campinas - baeninge@unicamp.br
\end{abstract}

Recebido em 06/04/2019. Aceito para publicação em 20/04/2019. Versão online publicada em 26/04/2019 (http://seer.ufrgs.br/paraonde)

Resumo: 0 objetivo desse trabalho é analisar os processos de redistribuição da população e as mudanças na estrutura do emprego associados à globalização do agronegócio no Estado de São Paulo. Como áreas privilegiadas de transformação social, espaços da globalização cujos vínculos transnacionais mais fortes passam pela produção de commodities, são apresentados os arranjos urbanos-rurais regionais. Nesse estudo, o enfoque recai nos arranjos construídos a partir dos circuitos espaciais produtivos dos setores sucroenergético, citrícola e de frigoríficos de carne bovina. Na condição de espacialidades híbridas, onde tendências históricas coexistem com novos processos, os arranjos urbanos-rurais regionais abrangem múltiplos espaços da migração que expressam toda a desigualdade e segmentação que marca a agricultura científica e globalizada e seu dinâmica de urbanização corporativa.

Palavras-chave: População rural; urbanização; globalização

Abstract: The objective of this work is to analyze the processes of redistribution of the population and the changes in the employment structure associated with the agribusiness globalization in the State of São Paulo. As privileged areas of social transformation, spaces of globalization whose strongest transnational links go through the production of commodities, regional urban-rural arrangements are presented. In this study, the focus is on the arrangements constructed from the productive space circuits of the sugarcane, citrus and beef slaughtering sectors. In the condition of hybrid spatiality, where historical trends coexist with new processes, regional urban-rural arrangements encompass multiple migration spaces that express all the inequality and segmentation that marks scientific and globalized agriculture and its dynamics of corporate urbanization.

Key-words: Rural population; urbanization; globalization 


\section{Introdução}

A expansão da agricultura científica e globalizada está associada a transformações no processo de urbanização do interior paulista (ELIAS, 2003). A instalação de circuitos espaciais produtivos globalizados (CASTILLO; FREDERICO, 2010) intensifica as formas de fragmentação do território (SANTOS, 2013), com a consolidação de arranjos espaciais eminentemente híbridos e multiescalas (MOURA, 2009), onde se verifica a sobreposição de verticalidades e horizontalidades, solidariedades orgânicas e organizacionais (SANTOS, 2013). Nesse cenário de reestruturação produtiva, a redefinição das complementaridades socioespaciais exige um olhar polivalente frente à inserção de cada localidade na hierarquia urbana regional, nacional e global (SANTOS, 2013). É desde essa perspectiva que as chamadas cidades do agronegócio (ELIAS, 2003) devem ser analisadas conjuntamente à emergências das periferias migrantes (PEREIRA; BAENINGER, 2016) e à articulação de diferentes espaços da migração (BAENINGER, 2012) no tecido urbano-rural regional.

No propósito de organizar uma análise articulada dessas diferentes centralidades, o trabalho discute a formação de distintos arranjos urbanos-rurais regionais na rede de cidades paulista, nos quais as transformações na estrutura do emprego (SASSEN, 1998; ELIAS, 2003) e nos processos de redistribuição da população (BAENINGER, 2012) despontam-se como dimensões fundamentais na compreensão dessas espacialidades. Diante da centralidade da produção de laranja, cana-de-açúcar e pecuária de corte, no Estado de São Paulo (ELIAS, 2003), são apresentados os arranjos articulados no bojo dos circuitos espaciais produtivos (CASTILLO; FREDERICO, 2010) dessas commodities.

Divido em três partes principais, esse artigo inicia-se pela discussão da relação entre globalização e redefinição das complementaridades socioespaciais que tradicionalmente acomodaram os processos de redistribuição da população em território nacional (BAENINGER, 2012). Em seguida, o debate volta-se à emergência de múltiplos espaços da migração em nível local e regional (BAENINGER, 2012) e às modificações na estrutura ocupacional decorrentes da expansão da agricultura científica e globalizada (ELIAS, 2003; SASSEN, 1998). A título de considerações finais, é reafirmado o caráter híbrido e multiescalar dos arranjos urbanos-rurais regionais.

\section{Globalização da agricultura e rede urbana}

O aumento da diferenciação funcional das cidades em áreas de expressiva produção de commodities consolida "organismos urbanos" (ELIAS, 2003, p.326) nos quais se verifica formas de coesão e solidariedades construídas a partir da instalação de circuitos espaciais produtivos globalizados (CASTILLO; FREDERICO, 2010). Valendo-se das rugosidades do espaço e de uma divisão socioespacial do trabalho prévia (SANTOS, 2002), a ação das corporações multinacionais seleciona lugares, inserindo-os desigualmente na "cadeia de produção de finanças" (SASSEN, 1998, p.70). A constituição de sistemas urbanos transnacionais (SASSEN, 1998), a partir do que Santos (2013) denominou de curto circuito da rede urbana, distingue-se pela não contiguidade espacial e reforço das interações entre o global e o local: "De um lado, a hiperescala da circulação do capital e das informações, e de outro, a hipoescala da localidade, onde se estabelece as relações de produção" (DINIZ, 2003,

ParaOnde!?, Porto Alegre, v.11, n.1, p.65-74, 2019. http://seer.ufrgs.br/paraonde

Edição Especial: "Geografia e transformações socioespaciais: dinâmicas agrárias e políticas do desenvolvimento regional” 
p.102).

Apesar da coesão imposta por esses atores globais comporem "o fundamento da existência e definição desses subespaços" (ELIAS, 2003, p.55-56), a inércia dinâmica das formas herdadas (SANTOS, 2002) alimenta uma série de resistências também importantes na análise desses espaços transnacionais (SASSEN, 1998). Despontam-se, assim, arranjos espaciais marcadamente híbridos, não coesos, qualitativamente distintos das regiões e aglomerações urbanas tradicionais (MOURA, 2009). No conjunto, a sobreposição de verticalidades e horizontalidades produz um tecido urbano-rural regional com múltiplas centralidades e localizações que rompem a relativa unidade espaço-temporal das formas regionais do período nacional desenvolvimentista (RIBEIRO, 2004).

A compreensão conjunta desses diferentes espaços da migração (BAENINGER, 2012) demanda a identificação de espacialidades que façam "sentido não apenas do ponto de vista da correlação de forças políticas, mas que incorpore as dimensões sociais, econômicas e demográficas" associadas a essas mudanças estruturais mais amplas (BAENINGER; OJIMA, 2008, p.131-132). Como áreas "privilegiadas de transformação social" (BAENINGER; OJIMA, 2008, p.136), espaços transnacionais cujos vínculos globais mais fortes passam pela produção de commodities (SASSEN, 1998), os arranjos urbanos-rurais regionais marcam tanto o hibridismo e o caráter multiescalar das formas espaciais características da atual fase de acumulação capitalista (MOURA, 2009), como dinâmicas regionais nas quais as aglomerações urbanas principais dependem de seu entorno rural disperso "para estabelecer contatos com a economia nacional e global" (ABRAMOVAY, 2000, p.27).

Ao instigar uma análise das interações socioespaciais entre campo e cidade em diversas escalas, os arranjos urbanos-rurais regionais diluem fronteiras engessadas por redes de articulação políticas, propondo uma reflexão das várias formas com que o rural regional conecta-se ao urbano local e ao sistema de cidades transnacional (SASSEN, 1998). A partir dessa perspectiva, o rural deixa de ser visto como resíduo, fadado ao desaparecimento por conta do processo de urbanização (ABRAMOVAY, 2000), para compor uma dimensão fundamental do processo de reestruturação produtiva em curso (ELIAS, 2003). Como estrutura socioespacial heterogênea, envolve tanto dinâmicas de reprodução social mais sustentáveis, com determinadas localidades rurais registrando inclusive aumento de população, como processos ligados cada vez mais à degradação ambiental decorrente da especialização produtiva e à evasão de população associada à expansão das commodities (KULCSÁR; CURTIS, 2012; RIELLA; MASCHERONI, 2006).

0 Mapa 1 apresenta os arranjos urbanos-rurais regionais da laranja, da cana-deaçúcar e da pecuária no Estado de São Paulo ${ }^{1}$. A localização dessas diferentes estruturas socioespaciais no território estadual expressa a centralidade das condições pretéritas e das rugosidades do espaço (SANTOS, 2002) em sua composição. Ainda que a pecuária tenha passado por investimentos que a alçou em outro patamar de produção, principalmente com a expansão dos frigoríficos e das exportações de carne brasileira, a importância dessa atividade no Oeste Paulista remete ao caráter excludente e pouco capitalizado de sua fronteira agrícola (TARTAGLIA; OLIVEIRA, 1988). Em contrapartida, a concentração dos arranjos da cana e da laranja a nordeste do estado, região que desde o momento histórico de sua ocupação capitalista é produtora de commodities integrada ao mercado internacional, reforça ser esse o segmento com maior densidade de vínculos entre agricultura/indústria e os principais veios de disseminação da agricultura científica e globalizada (ELIAS, 2003).

\footnotetext{
${ }^{1}$ A metodologia empregada na construção dos arranjos urbanos-rurais regionais, bem como os indicadores selecionados, encontra-se em Demétrio (2016).
}

Para0nde!?, Porto Alegre, v.11, n.1, p.65-74, 2019. http://seer.ufrgs.br/paraonde

Edição Especial: “Geografia e transformações socioespaciais: dinâmicas agrárias e políticas do desenvolvimento regional” 


\section{Mapa 1}

Arranjos urbanos-rurais regionais da laranja, cana-de-açúcar e pecuária

Estado de São Paulo, segundo municípios - 2006/2010

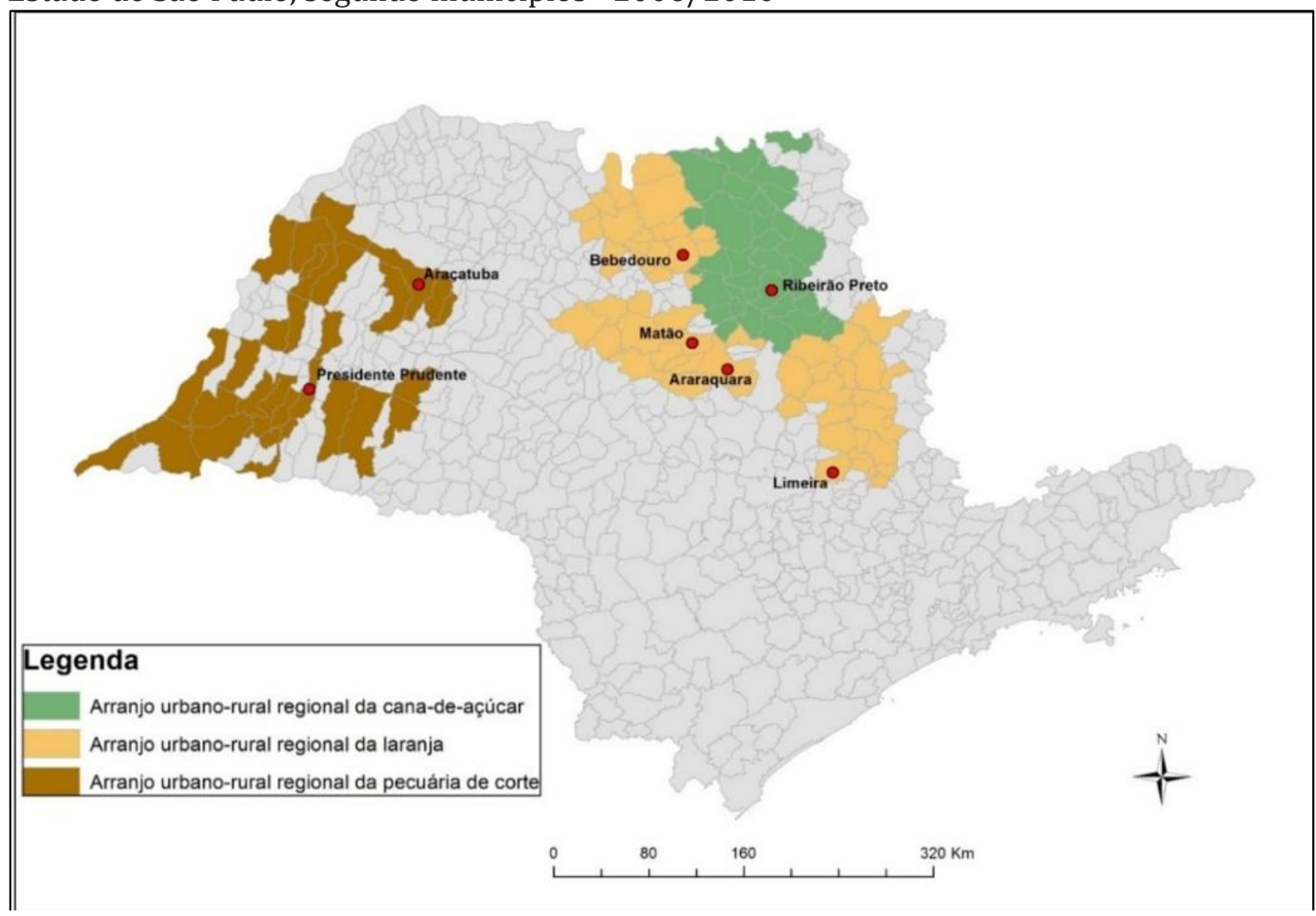

Fonte: Construído a partir de informações extraídas de FIBGE, Censo Agropecuário 2006 e Censo Demográfico 2010.

\section{As transformações na estrutura do emprego}

A formação de diferentes espaços da migração (BAENINGER, 2012) em nível local e regional também precisa ser analisada conjuntamente à tendência de crescente estratificação da estrutura do emprego (ELIAS, 2003; SASSEN, 1998). Para Elias (2003), o aprofundamento da divisão social do trabalho agropecuário reformulou a composição sócio ocupacional dessa atividade. Em paralelo à criaçãode novas ocupações de comando da produção, tem-se a expansão do trabalho precário, instável e mal remunerado. Por essa razão, uma das características centrais da agricultura científica e globalizada é seu caráter demasiadamente estratificado, que "tem numa ponta o proletário agrícola e na outra uma gama de trabalhadores especializados" (ELIAS, 2003b, p.330).

Segundo Bernardes (2007, p.9) e Riella e Mascheroni (2015), mesmo diante de um 
"nível técnico [...] menos exigente em quantidade de mão de obra", as áreas de expansão da agropecuária moderna concentram a geração de emprego, embora com pouca estabilidade, maior intensificação da exploração do trabalho e baixa qualidade quanto às garantias trabalhistas. As mudanças na forma de geração e distribuição de riquezas dão lugar o que Portes, Guarnizo e Landolt (2003) denominaram de globalização por cima (associada à proliferação dos cargos de controle) e de globalização por baixo, referente a todas as redes e estratégias construídas pelos trabalhadores em resposta à instabilidade e precariedade da inserção laboral.

Para uma análise do acirramento das desigualdades sócio ocupacionais na agropecuária paulista e a formação de diferentes espaços da migração no tecido urbanorural regionais, dois conceitos são fundamentais: o de trabalhadores do conhecimento (MELLO, 2007), como categoria que distingue uma série de ocupações alinhadas à inovação tecnológica e aos cargos de comando; e o de trabalhadores rurais migrantes (MACIEL, 2016), como categoria também fundamental à dinamização do agronegócio, mas condizente à globalização por baixo (PORTES; GUARNIZO; LANDOLT, 2003). A operacionalização desses dois grupos foi feita com base nas estimativas de vínculos empregatícios da Relação Anual de Informações Sociais (RAIS)2.

A evolução dos vínculos ativos nas ocupações selecionadas, nos arranjos urbanosrurais regionais da laranja, cana-de-açúcar e da pecuária, evidencia alterações importantes na estrutura do emprego desses setores. 0 arranjo da laranja, por exemplo, destaca-se pelo maior volume de contratos, tanto na categoria das ocupações qualificadas, quanto das não qualificadas (Tabela 1). Vale ressaltar que o aumento da demanda por trabalho qualificado contrasta-se com a diminuição dos vínculos ativos referentes às ocupações de menor qualificação: de quase 75 mil contratos em 2006, para 49.700 vínculos em 2010.

No arranjo urbano-rural regional da cana-de-açúcar, a evolução dos vínculos correspondentes ao grupo dos qualificados chama atenção pela oscilação registrada: a queda do volume desses contratos, entre 2006/2008 (de 1.060 para 1.033 vínculos), contrapõe-se ao aumento estimado entre 2008/2010, quando a demanda por trabalho qualificado volta a crescer e as ocupações nessa categoria fecham a série com 1.054 contratos. Já nas ocupações não qualificadas, o movimento de diminuição dos vínculos de trabalho foi persistente e paulatino: 31.554 contratos, em 2006; 29.637, em 2008; e 27.941, em 2010 (Tabela 1).

0 arranjo urbano-rural regional da pecuária, por fim, apresenta uma evolução do quadro sócio ocupacional bastante peculiar: os contratos em ambos os grupos registram aumento de vínculos (Tabela 1). Essa evidência empírica reforça a hipótese de concentração da criação de empregos nas áreas de recente expansão da agricultura globalizada (RIELLA; MASCHERONI, 2015; BERNARDES, 2007). Por outro lado, verifica-se diminuição dos vínculos entre os trabalhadores da pecuária de grande porte, fato indicativo da recomposição desse circuito espacial produtivo no estado de São Paulo (BINI, 2010).

\footnotetext{
${ }^{2}$ Para uma análise dessa fonte de informação e das categorias utilizadas, consultar Demétrio (2017).
} 
Tabela 1

Vínculos ativos em 31 de dezembro, segundo ocupações do agronegócio qualificadas e não qualificadas Arranjo urbano-rural regional da laranja, da cana-de-açúcar e da pecuária

2006,2008 e 2010

\begin{tabular}{|c|c|c|c|c|c|c|c|c|c|c|c|c|c|c|c|c|c|c|c|}
\hline & \multirow{3}{*}{ CBO 2002 Família } & \multicolumn{6}{|c|}{ Arranjo urbano-rural regional da laranja } & \multicolumn{6}{|c|}{ Arranjo urbano-rural regional da cana-de-açúcar } & \multicolumn{6}{|c|}{ Arranjo urbano-rural regional da pecuária } \\
\hline & & & $\mathbf{N}$ & & & $\%$ & & & $\mathbf{N}$ & & & $\%$ & & & $\mathbf{N}$ & & & $\%$ & \\
\hline & & 2006 & 2008 & 2010 & 2006 & 2008 & 2010 & 2006 & 2008 & 2010 & 2006 & 2008 & 2010 & 2006 & 2008 & 2010 & 2006 & 2008 & 2010 \\
\hline \multirow{12}{*}{ 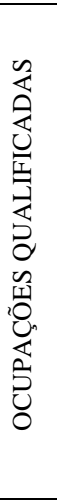 } & Diretores de produção e operações em empresa agropecuária & 15 & 14 & 14 & 1,01 & 0,88 & 0,85 & 9 & 12 & 10 & 0,85 & 1,16 & 0,95 & 6 & 4 & 5 & 1,24 & 0,66 & 0,77 \\
\hline & Gerentes de produção e operações em empresa agropecuária & 329 & 335 & 365 & 22,17 & 21,16 & 22,05 & 245 & 208 & 224 & 23,11 & 20,14 & 21,25 & 155 & 210 & 167 & 31,96 & 34,54 & 25,81 \\
\hline & Profissionais da biotecnologia & 1 & 1 & 1 & 0,07 & 0,06 & 0,06 & 16 & 19 & 11 & 1,51 & 1,84 & 1,04 & 1 & 0 & 0 & 0,21 & 0,00 & 0,00 \\
\hline & Pesquisadores das ciências da agricultura & 9 & 11 & 18 & 0,61 & 0,69 & 1,09 & 9 & 14 & 12 & 0,85 & 1,36 & 1,14 & 0 & 1 & 2 & 0,00 & 0,16 & 0,31 \\
\hline & Engenheiros agrimensores e engenheiros cartógrafos & 24 & 30 & 32 & 1,62 & 1,90 & 1,93 & 9 & 6 & 6 & 0,85 & 0,58 & 0,57 & 11 & 10 & 9 & 2,27 & 1,64 & 1,39 \\
\hline & Engenheiros agrossilvipecuarios & 366 & 421 & 452 & 24,66 & 26,60 & 27,31 & 231 & 233 & 254 & 21,79 & 22,56 & 24,10 & 75 & 101 & 116 & 15,46 & 16,61 & 17,93 \\
\hline & Veterinários e zootecnistas & 116 & 125 & 143 & 7,82 & 7,90 & 8,64 & 103 & 124 & 123 & 9,72 & 12,00 & 11,67 & 84 & 90 & 115 & 17,32 & 14,80 & 17,77 \\
\hline & Técnicos agrícolas & 535 & 547 & 536 & 36,05 & 34,55 & 32,39 & 413 & 385 & 378 & 38,96 & 37,27 & 35,86 & 138 & 169 & 214 & 28,45 & 27,80 & 33,08 \\
\hline & Técnicos florestais & 66 & 59 & 68 & 4,45 & 3,73 & 4,11 & 16 & 28 & 34 & 1,51 & 2,71 & 3,23 & 8 & 19 & 16 & 1,65 & 3,13 & 2,47 \\
\hline & Técnicos em aquicultura & 1 & 1 & 0 & 0,07 & 0,06 & 0,00 & 0 & 1 & 1 & 0,00 & 0,10 & 0,09 & 4 & 2 & 2 & 0,82 & 0,33 & 0,31 \\
\hline & Técnicos zootecnistas & 22 & 39 & 26 & 1,48 & 2,46 & 1,57 & 9 & 3 & 1 & 0,85 & 0,29 & 0,09 & 3 & 2 & 1 & 0,62 & 0,33 & 0,15 \\
\hline & Total & 1.484 & 1.583 & 1.655 & 100,00 & 100,00 & 100,00 & 1.060 & 1.033 & 1.054 & 100,00 & 100,00 & 100,00 & 485 & 608 & 647 & 100,00 & 100,00 & 100,00 \\
\hline \multirow{18}{*}{ 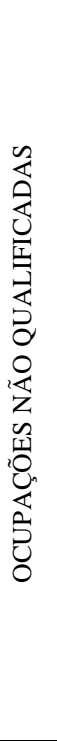 } & Trabalhadores de apoio à agricultura & 12.905 & 12.867 & 8.719 & 17,33 & 17,75 & 17,54 & 6.127 & 5.320 & 5.124 & 19,42 & 17,95 & 18,34 & 1.037 & 2.064 & 2.251 & 7,42 & 13,14 & 13,53 \\
\hline & Trabalhadores agrícolas na cultura de gramíneas & 13.742 & 10.350 & 10.428 & 18,46 & 14,28 & 20,98 & 17.391 & 15.597 & 13.604 & 55,12 & 52,63 & 48,69 & 8.008 & 7.623 & 7.643 & 57,30 & 48,53 & 45,93 \\
\hline & Trabalhadores agrícolas na cultura de plantas fibrosas & 23 & 16 & 16 & 0,03 & 0,02 & 0,03 & 21 & 3 & 5 & 0,07 & 0,01 & 0,02 & 1 & 3 & 0 & 0,01 & 0,02 & 0,00 \\
\hline & Trabalhadores agrícolas na olericultura & 864 & 138 & 81 & 1,16 & 0,19 & 0,16 & 31 & 31 & 39 & 0,10 & 0,10 & 0,14 & 21 & 42 & 38 & 0,15 & 0,27 & 0,23 \\
\hline & Trabalhadores agrícolas no cultivo de flores e plantas ornamentais & 3.194 & 2.742 & 2.978 & 4,29 & 3,78 & 5,99 & 16 & 70 & 28 & 0,05 & 0,24 & 0,10 & 50 & 73 & 24 & 0,36 & 0,46 & 0,14 \\
\hline & Trabalhadores agrícolas na fruticultura & 30.514 & 32.645 & 13.724 & 40,98 & 45,05 & 27,61 & 107 & 123 & 57 & 0,34 & 0,42 & 0,20 & 132 & 161 & 138 & 0,94 & 1,02 & 0,83 \\
\hline & Trabalhadores agrícolas nas culturas de plantas estimulantes e espec & 307 & 218 & 72 & 0,41 & 0,30 & 0,14 & 40 & 8 & 18 & 0,13 & 0,03 & 0,06 & 8 & 7 & 6 & 0,06 & 0,04 & 0,04 \\
\hline & Trabalhadores agrícolas na cultura de plantas oleaginosas & 26 & 22 & 20 & 0,03 & 0,03 & 0,04 & 58 & 130 & 62 & 0,18 & 0,44 & 0,22 & 8 & 18 & 20 & 0,06 & 0,11 & 0,12 \\
\hline & Trabalhadores de especiarias e plantas aromáticas e medicinais & 35 & 27 & 38 & 0,05 & 0,04 & 0,08 & 13 & 3 & 0 & 0,04 & 0,01 & 0,00 & 1 & 1 & 0 & 0,01 & 0,01 & 0,00 \\
\hline & Tratadores polivalentes de animais & 398 & 418 & 345 & 0,53 & 0,58 & 0,69 & 233 & 230 & 264 & 0,74 & 0,78 & 0,94 & 519 & 450 & 412 & 3,71 & 2,86 & 2,48 \\
\hline & Trabalhadores na pecuária de grande porte & 1.824 & 1.786 & 1.563 & 2,45 & 2,46 & 3,14 & 342 & 350 & 355 & 1,08 & 1,18 & 1,27 & 1.425 & 1.395 & 1.216 & 10,20 & 8,88 & 7,31 \\
\hline & Trabalhadores na pecuária de médio porte & 81 & 69 & 116 & 0,11 & 0,10 & 0,23 & 16 & 11 & 22 & 0,05 & 0,04 & 0,08 & 36 & 43 & 33 & 0,26 & 0,27 & 0,20 \\
\hline & Trabalhadores na pecuária de pequeno porte & 1.375 & 1.448 & 1.186 & 1,85 & 2,00 & 2,39 & 299 & 324 & 301 & 0,95 & 1,09 & 1,08 & 797 & 902 & 980 & 5,70 & 5,74 & 5,89 \\
\hline & Trabalhadores na criação de insetos e animais uteis & 47 & 35 & 20 & 0,06 & 0,05 & 0,04 & 0 & 247 & 235 & 0,00 & 0,83 & 0,84 & 8 & 94 & 33 & 0,06 & 0,60 & 0,20 \\
\hline & Trabalhadores da mecanização agropecuária & 9.022 & 9.577 & 10.260 & 12,12 & 13,21 & 20,64 & 6.692 & 7.029 & 7.736 & 21,21 & 23,72 & 27,69 & 1.896 & 2.752 & 3.820 & 13,57 & 17,52 & 22,96 \\
\hline & Trabalhadores da mecanização florestal & 59 & 62 & 42 & 0,08 & 0,09 & 0,08 & 127 & 123 & 77 & 0,40 & 0,42 & 0,28 & 26 & 74 & 20 & 0,19 & 0,47 & 0,12 \\
\hline & Trabalhadores da irrigação e drenagem & 40 & 51 & 101 & 0,05 & 0,07 & 0,20 & 41 & 38 & 14 & 0,13 & 0,13 & 0,05 & 3 & 7 & 6 & 0,02 & 0,04 & 0,04 \\
\hline & Total & 74.456 & 72.471 & 49.709 & 100,00 & 100,00 & 100,00 & 31.554 & 29.637 & 27.941 & 100,00 & 100,00 & 100,00 & 13.976 & 15.709 & 16.640 & 100,00 & 100,00 & 100,00 \\
\hline
\end{tabular}

Fonte: Relação Anual de Informações Sociais (RAIS) - Ministério do Trabalho e Emprego. Disponível em: http://bi.mte.gov.br/scripts10/dardoweb.cgi. Acesso: 28/02/2017.

Para0nde!?, Porto Alegre, v.11, n.1, p.55-64, 2019. http://seer.ufrgs.br/paraonde

Edição Especial: "Geografia e transformações socioespaciais: dinâmicas agrárias e políticas do desenvolvimento regional" 
Considerando as informações da RAIS por ramo de atividade e escolaridade ${ }^{3}$, reiterase o aumento dos vínculos com maior instrução, mesmo diante da tendência de redução no total de contratos (Tabela 2). Em termos relativos, o setor da pecuária e dos frigoríficos é o que apresenta maior proporção de pessoal com ensino superior completo. Em contrapartida, o segmento da citricultura e produção de suco registra a menor participação de trabalhadores com essa titulação, ao mesmo tempo em que o percentual de empregados sem instrução é significativamente mais alto que nos demais ramos. Em linhas gerais, os dados apresentados na Tabela 5 corrobora a hipótese segundo a qual, na atual fase do desenvolvimento capitalista, os postos de trabalho mais estáveis são justamente os que demandam maior escolaridade (BAENINGER, 2012; ELIAS, 2003).

Tabela 2

Vínculos ativos em 31 de dezembro nos setores citrícola, canavieiro e de pecuária de corte, segundo escolaridade Arranjos urbanos-rurais regionais da laranja, da cana-de-açúcar e da pecuária

Estado de São Paulo

2006, 2008 e 2010

\begin{tabular}{|c|c|c|c|c|c|c|c|}
\hline \multirow{2}{*}{ Arranjos } & \multirow{2}{*}{ Escolaridade } & \multicolumn{3}{|c|}{ Volume absoluto } & \multicolumn{3}{|c|}{ Participação relativa (em \%) } \\
\hline & & 2006 & 2008 & 2010 & 2006 & 2008 & 2010 \\
\hline \multirow{10}{*}{ 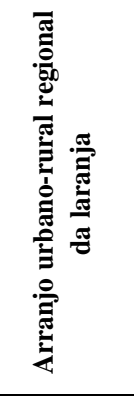 } & Analfabeto & 1.916 & 2.162 & 1.428 & 5,4 & 5,3 & 5,6 \\
\hline & Até $5^{\mathrm{a}}$ Incompleto & 6.400 & 7.723 & 4.019 & 17,9 & 18,8 & 15,8 \\
\hline & $5^{\text {a }}$ Completo Fundamental & 12.743 & 11.919 & 6.573 & 35,6 & 29,1 & 25,8 \\
\hline & $6^{a}$ a $9^{a}$ Fundamental & 5.038 & 6.685 & 3.154 & 14,1 & 16,3 & 12,4 \\
\hline & Fundamental Completo & 4.523 & 5.630 & 3.814 & 12,6 & 13,7 & 15,0 \\
\hline & Médio Incompleto & 1.322 & 1.784 & 1.396 & 3,7 & 4,4 & 5,5 \\
\hline & Médio Completo & 3.019 & 4.030 & 3.936 & 8,4 & 9,8 & 15,4 \\
\hline & Superior Incompleto & 184 & 265 & 284 & 0,5 & 0,6 & 1,1 \\
\hline & Superior Completo & 635 & 796 & 885 & 1,8 & 1,9 & 3,5 \\
\hline & Total & 35.780 & 40.994 & 25.489 & 100,0 & 100,0 & 100,0 \\
\hline \multirow{10}{*}{ 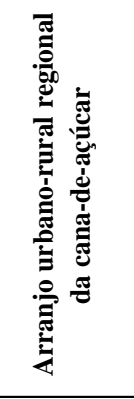 } & Analfabeto & 873 & 780 & 747 & 1,6 & 1,5 & 1,4 \\
\hline & Até $5^{\mathrm{a}}$ Incompleto & 10.293 & 8.848 & 7.698 & 19,4 & 17,2 & 14,9 \\
\hline & $5^{\mathrm{a}}$ Completo Fundamental & 11.064 & 10.984 & 10.492 & 20,8 & 21,3 & 20,3 \\
\hline & $6^{a}$ a $9^{a}$ Fundamental & 11.798 & 9.807 & 9.700 & 22,2 & 19,0 & 18,8 \\
\hline & Fundamental Completo & 5.328 & 5.212 & 5.533 & 10,0 & 10,1 & 10,7 \\
\hline & Médio Incompleto & 2.964 & 2.855 & 2.891 & 5,6 & 5,5 & 5,6 \\
\hline & Médio Completo & 8.454 & 10.292 & 11.569 & 15,9 & 20,0 & 22,4 \\
\hline & Superior Incompleto & 724 & 865 & 870 & 1,4 & 1,7 & 1,7 \\
\hline & Superior Completo & 1.685 & 1.840 & 2.091 & 3,2 & 3,6 & 4,1 \\
\hline & Total & 53.183 & 51.483 & 51.591 & 100,0 & 100,0 & 100,0 \\
\hline \multirow{10}{*}{ 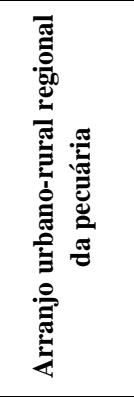 } & Analfabeto & 143 & 103 & 106 & 1,6 & 1,2 & 1,4 \\
\hline & Até $5^{\mathrm{a}}$ Incompleto & 1.188 & 923 & 792 & 13,6 & 10,6 & 10,2 \\
\hline & $5^{\mathrm{a}}$ Completo Fundamental & 1.543 & 1.346 & 1.069 & 17,7 & 15,4 & 13,8 \\
\hline & $6^{\mathrm{a}}$ a $9^{\mathrm{a}}$ Fundamental & 1.690 & 1.545 & 1.176 & 19,4 & 17,7 & 15,2 \\
\hline & Fundamental Completo & 1.653 & 1.839 & 1.562 & 19,0 & 21,1 & 20,2 \\
\hline & Médio Incompleto & 664 & 718 & 711 & 7,6 & 8,2 & 9,2 \\
\hline & Médio Completo & 1.411 & 1.781 & 1.828 & 16,2 & 20,4 & 23,6 \\
\hline & Superior Incompleto & 119 & 133 & 116 & 1,4 & 1,5 & 1,5 \\
\hline & Superior Completo & 310 & 344 & 385 & 3,6 & 3,9 & 5,0 \\
\hline & Total & 8.721 & 8.732 & 7.745 & 100,0 & 100,0 & 100,0 \\
\hline
\end{tabular}

Fonte: Relação Anual de Informações Sociais (RAIS) - Ministério do Trabalho e Emprego. Disponível em: http://bi.mte.gov.br/scripts10/dardoweb.cgi. Acesso: 19/02/2017.

Em síntese, as estatísticas coletadas pela RAIS reafirmam a hipótese de maior estratificação da estrutura ocupacional do agronegócio paulista (ELIAS, 2003), com mudanças na forma de geração e distribuição de riquezas que remetem tanto a uma

\footnotetext{
${ }^{3}$ A descrição das classes de atividades que compõe os segmentos agroindustriais da laranja, cana-de-açúcar e pecuária de corte encontra-se em Demétrio (2017).
} 
globalização por cima, como uma globalização por baixo (PORTES; GUARNIZO; LANDOLT, 2003). É nesse sentido que a agricultura científica e globalizada (ELIAS, 2003) conjuga trabalhadores do conhecimento (MELLO, 2007) e trabalhadores rurais migrantes (MACIEL, 2016), os quais conformam diferentes espaços da migração (BAENINGER, 2012) 4.

\section{Considerações Finais}

O estudo aqui realizado possibilitou apreender as novas faces do rural paulista e suas articulações locais, regionais e globais no século 21. Através dos arranjos urbanos-rurais regionais, construídos com base justamente nos vínculos com a produção agrícola globalizada de commodities, pode-se analisar as alterações na dinâmica da própria rede urbana, na dinâmica da estrutura do emprego agrícola e na dinâmica da população e das migrações. Nesse contexto, o tecido urbano-rural regional é multifacetado, híbrido, de múltiplas centralidades e localizações. A produção desses espaços expressa a desigualdade e segmentação que marca a agricultura científica e globalizada e seu processo de urbanização corporativa (ELIAS, 2003). Conjuntamente aos processos herdados, às rugosidades do passado (SANTOS, 2002), o rural atual em São Paulo se define pelo agronegócio globalizado, redesenhando espaços e conformando arranjos urbanos-rurais regionais no século 21 .

\section{Referências Bibliográficas Principais}

ABRAMOVAY, R. Funções e medidas da ruralidade no desenvolvimento contemporâneo. Texto para discussão $n^{-}$702. IPEA: Rio de Janeiro, p.1-31, 2000.

BAENINGER, R. São Paulo e suas migrações no final do século XX. São Paulo em Perspectiva, v.19, n.3, p.84-96, jul./set. 2005.

BAENINGER, R. Fases e faces da migração em São Paulo. Campinas: Núcleo de Estudos de População - NEPO/UNICAMP, 2012.

BAENINGER, R.; OJIMA, R. Novas territorialidades e a sociedade de risco: evidências empíricas e desafios teóricos para a compreensão dos novos espaços da migração. Papeles de Población, v.58, p.141-154, 2008.

BERNARDES, J. A. Modernização agrícola e trabalho no Cerrado brasileiro. Scripta Nova, v. XI, n.245, 2007.

BINI, D. L. de C. Mudanças na pecuária de corte e algumas implicações sócio-espaciais na Região de Araçatuba (SP). Revista Formação, n.16, v.2, 2010.

BRANDÃO, C. A. Território e desenvolvimento: as múltiplas escalas entre o local e o global. Campinas, Editora da UNICAMP, 2007.

CASTILLO, R. Dinâmicas recentes do setor sucroenergético no Brasil: competitividade regional e expansão para o Bioma Cerrado. GEOgraphia - Ano 17 - № 35 - Dossiê, 2015.

CASTILLO, R.; FREDERICO, Samuel. Espaço geográfico, produção e movimento: uma reflexão sobre o conceito de circuito espacial produtivo. Sociedade \& Natureza, Uberlândia, 22 (3): 461-474, dez. 2010.

DELGADO, G. Mudança técnica na agricultura, constituição do complexo agroindustrial e política tecnológica recente. Cadernos de Ciência \& Tecnologia, Brasília, 2(1): 79-97, jan. /abr., 1985.

DEMÉTRIO, N. B. Arranjos urbanos-rurais regionais: o rural paulista no século 21. Tese de

\footnotetext{
${ }^{4}$ Os trabalhos de Pereira (2015) e Maciel (2013) são exemplos de pesquisas que esclarecem o lugar dos trabalhadores rurais migrantes da laranja nos municípios de Matão e São Carlos.
}

Para0nde!?, Porto Alegre, v.11, n.1, p.65-74, 2019. http://seer.ufrgs.br/paraonde Edição Especial: “Geografia e transformações socioespaciais: dinâmicas agrárias e políticas do desenvolvimento regional” 
doutorado. Campinas: Instituto de Filosofia e Ciências Humanas - IFCH/UNICAMP, 2017. DINIZ, C. C. Repensando a questão regional brasileira: tendências e desafios. In: ACUÑA, C.; RIELlA, A. (Org). Território, Sociedad y Región: Perspectivas desde el Desarrollo Regional y Local. Montevideo: Faculdad de Ciencias Sociales, 2003.

ELIAS, D. Globalização e Agricultura. São Paulo: EdUSP, 2003.

ELIAS, D. Agricultura científica no Brasil: impactos territoriais e sociais. In: SOUZA, M. A. A. de (org.) Território brasileiro: usos e abusos. Campinas: Territorial, 2003b.

GIDDENS, A. As consequências da modernidade. São Paulo: Editora UNESP, 1991.

GONÇALVES, M. F. As engrenagens da locomotiva: ensaio sobre a formação urbana paulista. Tese de doutorado. Campinas: Instituto de Filosofia e Ciências Humanas - IFCH/UNICAMP, 1998.

KULCSÁR, L. J.; CURTIS, K. J. Why does rural demography still matter? In: KULCSÁR, L. J.; CURTIS, K. J. (Eds.). Internetional Handbook of Rural Demography. London/New York: Springer, 2012.

MACIEL, L. M. O Sentido de Melhorar de Vida: Arranjos familiares na migração rural-urbana para o interior de São Paulo. Jundiaí: Paco Editorial, 2013.

MACIEL, L. M. Entre o rural e o urbano: processos migratórios de trabalhadores rurais do Alto Médio Canindé piauiense para região central do Estado de São Paulo. Tese de Doutorado. Campinas: Instituto de Filosofia e Ciências Humanas - IFCH/UNICAMP, 2016.

MAZZALI, L. O processo recente de reorganização agroindustrial: do complexo à organização 'em rede'. São Paulo: Editora UNESP, 2000.

MELLO, L. F. Trabalhadores do Conhecimento e Qualidade do Lugar em Campinas, SP. Tese de Doutorado. - Universidade Estadual de Campinas, Instituto de Filosofia e Ciências Humanas, 2007.

MELO, B. M. de. História e memória na contramão da expansão canavieira: um estudo das formas de resistência dos sitiantes do extremo noroeste paulista. Tese de Doutorado. São Carlos: UFSCAR, 2013.

MOURA, R. Arranjos urbano-regionais no Brasil: uma análise com foco em Curitiba. Tese de doutorado. Curitiba: Programa de Pós-Graduação em Geografia. Universidade Federal do Paraná, 2009.

PEREIRA, G. G. Entre o partir e o chegar: os trabalhadores rurais migrantes em Matão/SP. Dissertação de Mestrado. Campinas: Instituto de Filosofia e Ciências Humanas IFCH/UNICAMP, 2015.

PEREIRA, G.; BAENINGER, R. Periferias Migrantes: Trabalhadores Rurais do Agronegócio Citrícola em São Paulo (Brasil). Anais do VIII Congresso Latinoamericano de Estudos do Trabalho. Buenos Aires, 3 a 5 de agosto de 2016.

Portes, Guarnizo e Landolt (2003)

RIBEIRO, A. C. T. Regionalização: fato e ferramenta. In: LIMONAD, E.; HAESBAERT, R.; MOREIRA, R. (org.) Brasil século XXI: Por uma regionalização? Processos, Escalas, Agentes. São Paulo: Max Limonad, 2004. p. 194-212.

RIELlA, A.; MASCHERONI, P. (Org). Asalariados Rurales em América Latina. Consejo Latinoamericano de Ciencias Sociales e Departamento de Sociología-FCS-UDELAR, 2015.

RIELLA, A.; MASCHERONI, P. Desigualdades sociales y territorios rurales en Uruguay. Revista Pampa, 2011.

RODRIGUES, I. A. A Demografia da Vida Rural Paulista. Tese de doutorado. Campinas: Instituto de Filosofia e Ciências Humanas - IFCH/UNICAMP, 2001.

SANT'ANA, A. L.; SILVA, F. C. da; MODENESE, V. da S.; SANT'ANA, D. Z.; SOUZA, G. dos S. Qualidade partilhada e relações de sociabilidade entre produtores familiares e 
consumidores no processo de comercialização direta, no noroeste paulista. In: CONTERATO; M. A.; NIERDELE, P. A.; TRICHES, R. M.; MARQUES, F. C.; SCHULTZ, G. Mercados e Agricultura Familiar: Interfaces, Conexões e Conflitos. Porto Alegre: Via Sapiens, 2013.

SANTOS, M. A Natureza do Espaço: Técnica e Tempo, Razão e Emoção. São Paulo: Editora da Universidade de São Paulo, 2002.

SANTOS, M. Técnica, espaço, tempo. São Paulo: Editora da Universidade de São Paulo, 2013 (5 $5^{\text {a }}$ ed.).

SASSEN, S. As cidades na economia mundial. São Paulo: Studio Nobel, 1998.

SILVA, J. G. da. O novo rural brasileiro. Campinas: UNICAMP. IE, 1999.

SINGER, P. Migrações internas: considerações teóricas sobre o seu estudo. In: MOURA, H. (Org.). Migração interna: textos selecionados. Fortaleza: Banco do Nordeste do Brasil S.A., 1980.

TARTAGLIA, J.C; OLIVEIRA, O. L. Agricultura Paulista e sua Dinâmica Regional (1920-1980). In: CANO, W. (Org.). A interiorização do desenvolvimento econômico no Estado de São Paulo (1920-1980). São Paulo: SEADE, 1988, p.5-93. 